\title{
The 2016 Kumamoto Earthquake on April 16 and Our Actions
}

\author{
9 May, 2016 \\ Takashi Onishi, President, Science Council of Japan \\ Akira Wada and Noriaki Hirose \\ Representative Directors, Japan Academic Network for Disaster Reduction
}

Science Council of Japan (SCJ) and Japan Academic Network for Disaster Reduction (JANET$\mathrm{DR}$, a network of 50 academic societies related to disaster reduction) would like to express our condolences for the people who lost lives in the Kumamoto Earthquake and offer our heartfelt sympathies for those affected by the disasters. And, we also would like to express our gratitude for the helps and sympathies offered by our colleagues abroad. We would like to urgently report what occurred in Kumamoto and what actions were taken by SCJ and JANET-DR so far.

A series of strong earthquakes attacked Kumamoto and Oita Prefectures in central Kyushu in the mid of April. The severe casualties and damages were reported: 49 killed, one missing, 18 disaster-related deaths, 1,600 wounded, 63 thousand houses collapsed or damaged, and 15 thousands evacuated as of 6 May (183 thousands on 17 April). The first strong earthquake was recorded at 21:26, 14 April, 2016, in Mashiki Town, Kumamoto. Then, after many small-scale aftershocks, the strongest shock occurred 1:45, 16 April in the same town, which was called the main shock of "the 2016 Kumamoto Earthquake". The hypocenters of those earthquakes are situated at shallow depth in Futagawa and Hinagu fault zones, two of the most prominent active faults in Kyushu region. The displacement of those faults caused more than 1,000 shocks at various seismic intensity in Kumamoto areas.

The pictures shown on the document No. 1 were taken at the sites, which showed a strikeslip fault appeared on a paddy field, wooden houses collapsed in Mashiki Town, landslides in Minami-Aso Village and the collapse of Aso-Ohashi road-bridge presumably caused by landslide.

It is obvious that strong shocks caused by the displacement of the active faults in the vicinity destroyed mainly old wooden houses which didn't fit the current seismic design standards and killed many people inside them. Some of buildings and infrastructure facilities, however, which are supposed to possess adequate seismic capacity were also damaged. The damage of the earthquake differs according to the geographical feature and the situation of ground. Therefore, further investigation must be done.

Some of the members of SCJ and JANET-DR went to the disaster area for the urgent investigation and had two opportunities to report what learnt from these disasters.

Firstly, the emergency joint press conference was held on April 18, at the meeting room of Japan Society of Civil Engineers with the participation of 43 journalists in order to transfer the accurate information of the earthquakes and disasters caused by them from the academics to the media as shown on the document No. 2. As a result, many views of experts attended in the conference as speakers were cited in many articles. 
Secondly, the urgent report meeting was held on May 2, at SCJ auditorium with the lectures from 17 societies and more than 300 participants including 54 journalists as shown on the same document No. 2. The lectures on the investigation were made by experts of many societies;

The Seismological Society of Japan,

The Japanese Society for Active Fault Studies,

The Japanese Geotechnical Society,

The Association of Japanese Geographers,

Geographic Information Systems Association of Japan,

Japan Society of Civil Engineers,

Architectural Institute of Japan,

Japan Association of Earthquake Engineering,

The Japanese Society of Irrigation, Drainage and Rural Engineering,

Japan Society of Engineering Geology,

The Japan Landslide Society,

Japan Society of Erosion Control Engineering,

Japan Society of Disaster Nursing,

Japanese Association of Disaster Medicine,

Japan Association of Planning and Public Management,

Japan Society for Disaster Recovery and Revitalization, and

Japan Society of Material Cycles and Waste Management.

We would like to appreciate the experts who made precious reports for the understandings, lessons and scientific ideas for the further research.

The followings were stressed through lectures and discussions as what we have to:

1. Understanding and even predicting the further development of the present activities of the active faults. Especially, finding how the series of earthquakes will affect other active faults or subduction-zones is what the society wants to know.

2. Understanding the expansion of landslide in mountainous areas where landslides took place due to the earthquakes.

3. Understanding how the continuous two peaks of large-scale shocks affected the destruction of man-made structures.

4. Considering how we can reduce the people's anxieties or fears caused by the earthquakes.

5. Considering how we can propagate practical disaster-reduction measures, as the Kumamoto earthquake is likely to occur anywhere in Japan.

6. Considering how we can accelerate recovery and reconstruction making use of the past experience of disasters such as effective measures in loss of power, in evacuation center management, and so on.

7. Strongly recommending retrofitting old buildings and housing, everywhere in Japan, which do not have the seismic capacity to withstand earthquakes.

We will have another report meeting when our societies finish their initial field survey hopefully in July. 


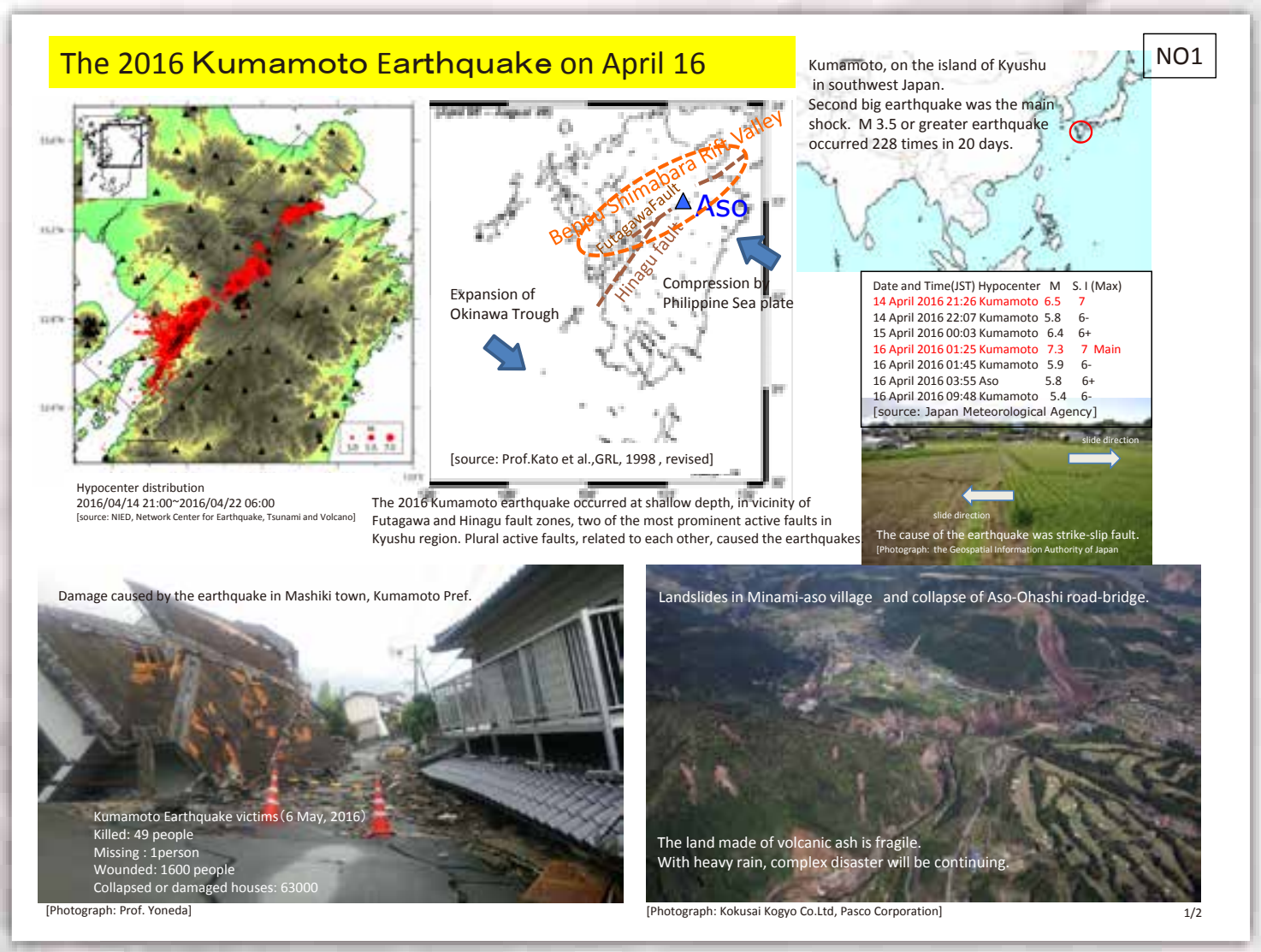

First response to Kumamoto earthquake

Science Council of Japan (SCJ) \& Japan Academic Network for Disaster Reduction (JANET-DR)
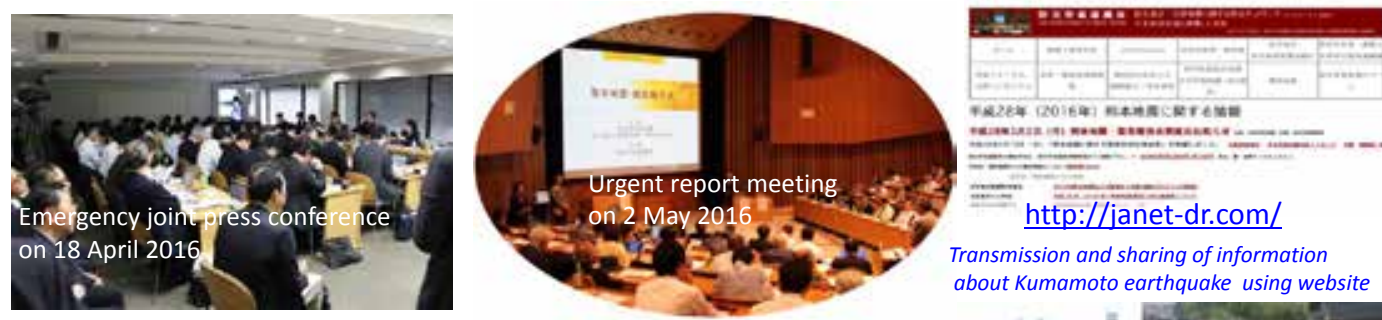

TQ2E⿰亻⿻

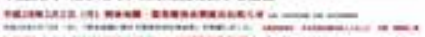
$=\frac{-}{\text { http://ianet-dr.com/ }}$ Transmission and sharing of information about Kumamoto earthquake using website

- Experts of different fields gathered and made the opportunity to answer a variety of questions about Kumamoto earthquake.

- Accurate information was transferred from academies to media. Total 97 journalists attended and cited the opinions of experts in many articles.

- Providing the opportunity for each society to explain the report of urgent investigation. - Promoting understanding of Kumamoto earthquake and disaster by sharing information among different academic societies.

-Promoting interdisciplinary cooperation for disaster reduction and disaster restoration.
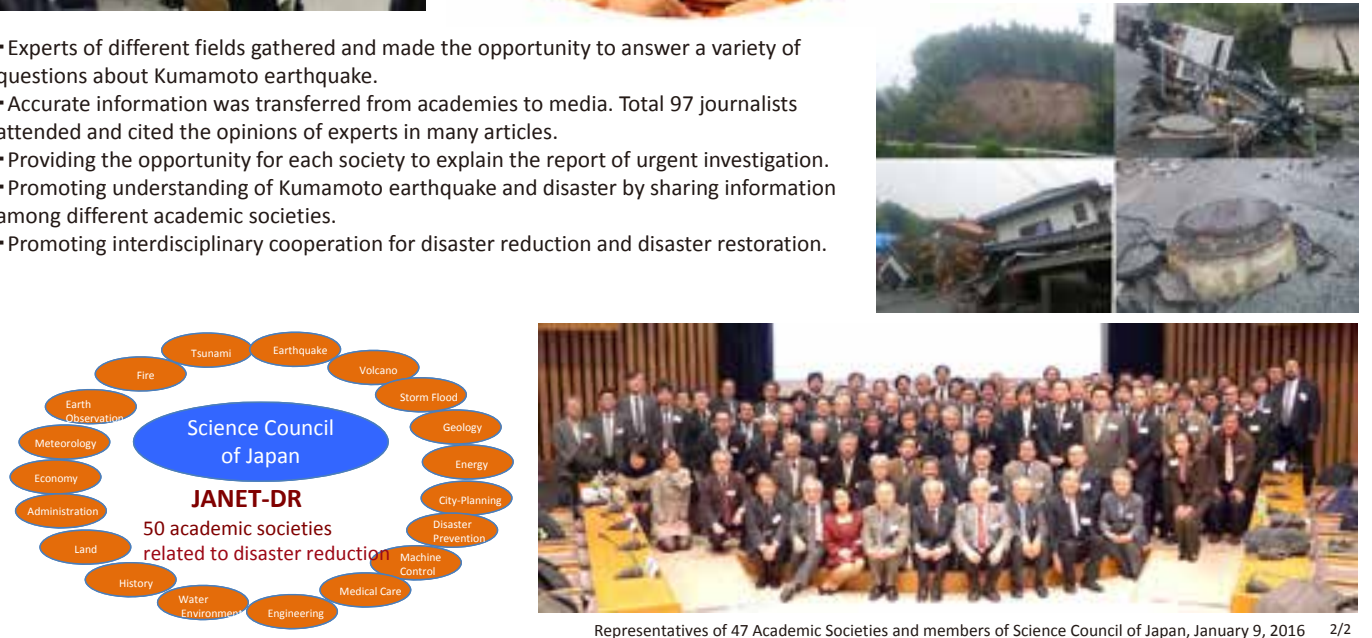

Representatives of 47 Academic Societies and members of Science Council of Japan, January 9, $2016 \quad 2 / 2$ 